\title{
Two-Dimensional Gel Electrophoresis Reveals Differential Protein Expression Between Individual Daphnia
}

\author{
Darren J. Bauer, Gary B. Smejkal and W. Kelley Thomas \\ Hubbard Center for Genome Studies, University of New Hampshire
}

USA

\section{Introduction}

Analysis of individual genetic variation is paramount to understanding how organisms and communities respond to changes in the environment and requires a model system with well-developed molecular resources and a solid foundation of ecological knowledge. Traditional genetic model systems (E. coli, yeast, fly, worm, and mouse) have served as workhorses in elucidating virtually all of the knowledge in modern molecular biology. While these systems were chosen for their robustness in laboratory studies, virtually nothing is known about their life histories in their native environment. By contrast, newmodel systems, which have typically been studied in depth, from an ecological perspective are severely limited in regards to their molecular resources.

The model organism Daphnia has been utilized as an ecological model for centuries, and now with the sequencing of the genome complete and the development of the associated molecular resources, it is poised as one of the few model systems with the necessary molecular and ecological tools to answer the questions of response to the environment (Colborne et al., 2011). Long recognized as a model for ecological research, the freshwater crustacean Daphnia is rapidly maturing into a powerful model for understanding basic biological processes, within an ecological context. A common resident of lakes and ponds, Daphnia has been the subject of over a century of study in the areas of rapid environmental response, physiology, nutrition, predation, parasitology, toxicology and behavior (Edmondson, 1987). The reproductive cycle of Daphnia is ideal for experimental genetics. Generation time in the laboratory rivals that of almost all other model eukaryotic systems, reaching maturity within 5-10 days. Under favorable environmental conditions, Daphnia reproduce through parthenogenesis, allowing the conservation of genetic lines. Sexual reproduction is induced by environmental changes allowing the production of inbred or outbred lineages. The sexually produced diapausing eggs, termed ephippia, can be stored viably for considerable periods. Moreover, they have been hatched from lake sediments up to a century old (Hairston et al., 2001; Limburg \& Weider, 2002) allowing tracking of genetic changes over ecological and evolutionary time scales. Daphnia are transparent throughout life, allowing for studies of tissue-specific gene expression at any life stage and direct observation of parasites and pathogens. As a result, there is a growing body of work in 
Daphnia related to regulation of developmental genes, the genetic basis of evolutionary ecology, and parasite resistance and immunity.

Understanding and predicting how individual organisms respond at the molecular level to environmental change will provide new insight into the evolution of complex biological systems. This insight will lead to the development of new predictive models of hostpathogen interactions, environmental stress and community dynamics as a function of environment and genotype/phenotype (National Science Board, 2000) advancing the field of individualized molecular medicine. As the number of organisms with complete genome sequence increases and technological improvements allow more sequence to be generated at a lower cost, the ability to look at genetic variation in a variety of organisms is greater than ever. However, to understand the role of genetic variation in the context of the natural environment, a model system with two critical components, (1) well-developed molecular resources and (2) a well-understood ecological knowledge base, is essential. Until recently, model systems typically possessed one of these components in depth while the other was nominal or lacking altogether. The recent sequencing of the entire Daphnia pulex genome and the establishment of the still growing molecular toolbox (ESTs, genetic map, arrays, etc.) represents the first model system with both components in place.

Organisms respond to environmental change through relatively quick changes in gene expression or through evolutionary response over multiple generations. To better comprehend the effect of gene expression on phenotype, an understanding of genetic variation for gene expression is necessary. A comprehensive understanding of genetic variation is obtained by sampling between and within populations, including individual organisms, directly from their natural environment. The well-documented ecological understanding of Daphnia makes the system uniquely suited to this and allows researchers to collect and sample individuals of wild populations directly from their native environment.

Our goal was to demonstrate that it is possible to detect biologically relevant variation in protein expression from an individual Daphnia. Using pressure cycling technology (PCT) for sample preparation and two-dimensional gel electrophoresis (2-DE), we have demonstrated that differences in protein expression between individual Daphnia with distinct genotypes and exhibiting biologically relevant phenotypic differences are detectable. The ability to detect and analyze individual differences for a large number of proteins represents an important step towards understanding the connection between genotype/phenotype and the environment.

\section{Materials and methods}

\subsection{Daphnia and algae cultures}

\subsubsection{Algae cultures}

Starter cultures of the green algae Ankistrodesmus falcatus were obtained from UTEX, The Culture Collection of Algae at The University of Texas (Austin, TX, USA). A. falcatus was grown in $2 \mathrm{~L}$ aerated, air-filtered culture vessels containing GTk media at $25^{\circ} \mathrm{C}$ under continuous illumination. GTk contains the following macronutrients, $0.2 \mathrm{mM} \mathrm{CaCl}_{2}, 2.5 \mathrm{mM}$ $\mathrm{KNO}_{3}, 0.3 \mathrm{mM} \mathrm{MgSO}_{4}, 0.4 \mathrm{mM} \mathrm{Na}_{2} \mathrm{HPO}_{4}$ and the following micronutrients, $150 \mu \mathrm{M}$ EDTA, 
$\mathrm{Na}_{2}, 20 \mu \mathrm{M} \mathrm{FeSO}_{4}, 2 \mu \mathrm{M} \mathrm{ZnSO}_{4}, 1 \mu \mathrm{M} \mathrm{NaMoO}, 0.6 \mu \mathrm{M} \mathrm{CuSO}_{4}, \mathrm{CoCl}_{2}$ and $14 \mu \mathrm{M} \mathrm{MnCl}$ (Leland Jahnke, Personal Communication).

\subsubsection{D. magna with unique phenotype}

D. magna starter cultures were obtained from Sachs Systems Aquaculture (St. Augustine, FL, USA). Stabilized cultures were maintained in $8 \mathrm{~L}$ of $25 \%$ mineralized water (Vermont Spring Water Company, Brattleboro, VT, USA) at a density of 60-120 individuals/L. D. magna were cultured at $22^{\circ} \pm 1^{\circ} \mathrm{C}$ under constant illumination with standard fluorescent bulbs. Cultures were maintained at $\mathrm{pH}$ 7.0-7.4 by the addition of $100 \mathrm{~g} / \mathrm{L}$ crushed coral (Tideline Aquatics, Hanahan, SC, USA) supplied in nylon bags. Starter cultures were fed daily with $1 \mathrm{~mL} / \mathrm{L}$ of Nanochloropsis microalgae liquid concentrate (Reed Maricultures, Campbell, CA, USA) for the first four weeks, followed by $0.1 \mathrm{~mL} / \mathrm{L}$ thereafter.

\subsubsection{D. magna with unique genotype and $D$. pulex}

D. magna clones Iinb1 and Xinb3 were isolated from Munich, Germany and Tvärminne, Finland, respectively (Rottu et al., 2010). D. pulex clone Log50 was obtained from the Daphnia Genomics Consortium stock (www.wfleabase.org/stocks). Xinb3 and Log50 are the clones for the respective, D. magna and D. pulex genome projects. Cultures were maintained in $8 \mathrm{~L}$ of COMBO media (Killham et al., 1998) at a density of 30 individuals/L at $20^{\circ} \pm 1^{\circ} \mathrm{C}$ under a 16:8 hours, light:dark, low intensity photoperiod, and fed $1 \mathrm{mg}$ Carbon/L of $A$. falcatus.

\subsection{Harvesting of Daphnia}

Daphnia gut contents were minimized by allowing the microcrustaceans to feed on copolymer microspheres of 4.3-micron mean diameter (Duke Scientific, Fremont, CA, USA) for one hour prior to harvesting. Microspheres were fed at a concentration equal to the number of algal cells previously supplied. Daphnia were harvested by filtration through 250 um Nitex mesh (Sefar America, Depew, NY, USA) and flash frozen. Average mass of adult Daphnia pulex was $0.1158 \pm 8.3 \mathrm{mg}$ fully hydrated and $0.05285 \pm 10.60 \mathrm{mg}$ dehydrated $(n=$ $50)$. Average mass of adult $D$. magna was $1.37 \pm 0.46 \mathrm{mg}$ fully hydrated and $0.23 \pm 0.06 \mathrm{mg}$ when dehydrated $(n=64)$.

\subsection{Pressure Cycling Technology (PCT)}

PCT has been shown to be an effective means for isolating proteins from a variety of microorganisms, as well as many difficult-to-lyse samples such as Caenorhabditis elegans (Geiser et al., 2002; Smejkal et al., 2006b; Smejkal et al., 2007). PCT, which subjects samples to rapid cycles of pressure, facilitated the extraction of proteins from single Daphnia magna with and without ephippia and from single Daphnia pulex.

Daphnia were transferred to tared PULSE Tubes (Pressure BioSciences, Inc., South Easton, MA, USA) and suspended in $500 \mathrm{uL}$ of $7 \mathrm{M}$ urea, $2 \mathrm{M}$ thiourea, and $4 \%$ CHAPS supplemented with $100 \mathrm{mM}$ dithiothreitol (DTT) and protease inhibitor cocktail P-2714 (Sigma Aldrich Chemicals, St. Louis, MO). An additional $900 \mathrm{uL}$ of mineral oil was added to accommodate the necessary volume for the PULSE Tubes. The tubes were placed in the Barocycler NEP-3229 (Pressure BioSciences, Inc., South Easton, MA, USA) for 60 pressure 
cycles, each cycle consisting of 10 seconds at 35,000 psi followed by rapid depressurization and held for 2 seconds at atmospheric pressure. Following PCT, each PULSE Tube was coupled to an Ultrafree-CL centrifugal filtration device with a 5-micron pore size (Millipore Corporation, Danvers, MA, USA) and evacuated by centrifugation for 1 minute at 1000 RCF. The PULSE Tube was removed and centrifugation continued for 4 minutes at $4000 \mathrm{RCF}$, followed by the removal of the mineral oil.

\subsection{Reduction, alkylation, and ultrafiltration}

Samples were transferred to ULTRA-4 ultrafiltration devices with $10 \mathrm{kDa}$ molecular weight cut-off (Millipore Corporation, Danvers, MA, USA). Proteins larger than $10 \mathrm{kDa}$ are retained in the ultrafiltration device. Centrifugation assisted the ultrafiltration, and the samples were exchanged with fresh UTC until the final DTT concentration was $10 \mathrm{mM}$. Reduction and alkylation of the samples were performed directly in the ultrafiltration devices using $5 \mathrm{mM}$ tributylphosphine and $50 \mathrm{mM}$ acrylamide as described (Smejkal et al., 2006a). The alkylation reaction was terminated by resuming centrifugation and ultrafiltrative exchange. Bradford Reagent (Sigma-Aldrich Chemicals, St. Louis, MO, USA) was used to measure the protein concentration in each sample.

\subsection{IEF and 2-DE}

Two-hundred $\mathrm{uL}$ of each sample was placed onto individual wells in IPG rehydration trays from Proteome Systems (Woburn, MA, USA). Bio-Rad ReadyStrip IPG strips with a $\mathrm{pH}$ range of 3-10, 4-7, or 7-10 (Hercules, CA, USA) were placed onto each sample, and the tray was placed into a humidifying Ziploc bag. Rehydration occurred over six hours until all the sample was visibly absorbed by the strip. At the termination of rehydration, strips were placed into isoelectric focusing trays and ran at 10,000 volts (maximum voltage) for 110,000 accumulative volt-hours. Strips were equilibrated twice for 10 minutes in $375 \mathrm{mM}$ Tris- $\mathrm{HCl}$ containing $2.5 \%$ SDS, 3M urea, $0.01 \%$ and phenol red, then placed onto Criterion Tris- $\mathrm{HCl} 8$ 16\% IPG+1 gels (Bio-Rad Laboratories, Hercules, CA) and ran at $120 \mathrm{~V}$ and $60 \mathrm{~mA} / \mathrm{gel}$. 2-DE gels were ran for all IPGs, only 4-7 gels are shown.

\subsection{Digital image analyses}

The 24-bit images were analyzed using PDQuest ${ }^{\mathrm{TM}}$ software (Bio-Rad, v.7.1). Background was subtracted, and protein spot density peaks were detected and counted. A reference pattern was constructed from one of the individual gels to which each of the gels in the matchset was matched. Numerous proteins that were uniformly expressed in all patterns were used as landmarks to facilitate rapid gel matching. After matching, the total spot count was determined for each gel.

\section{Results and discussion}

\subsection{Protein variation between individual $D$. magna of distinct genotypes}

Our first goal was to demonstrate that differences in protein expression could be detected between individual Daphnia of distinct genotypes. Individual D. magna from Iinb1 and Xinb3 genotypes were isolated, proteins extracted and analyzed in quadruplicate by 2-DE as 
describe above. Silver staining detected an average of $687 \pm 11$ protein spots from the Xinb3 gels and $692 \pm 14$ protein spots from the linb1 gels (figure 1). After normalization of the gel images based on total intensity, 679 spots were matched between the two gel images. One Hundred thirty six spots showed a two-fold or greater difference in spot intensity. Seventynine of these were more abundant in Xinb3 and 57 were more abundant in the Iinb1. To illustrate these differences, the silver stained gels were digitally colored. The Iinb1 gels were red and the Xinb3 gels were green. The gels were then superimposed. (Figure 2).

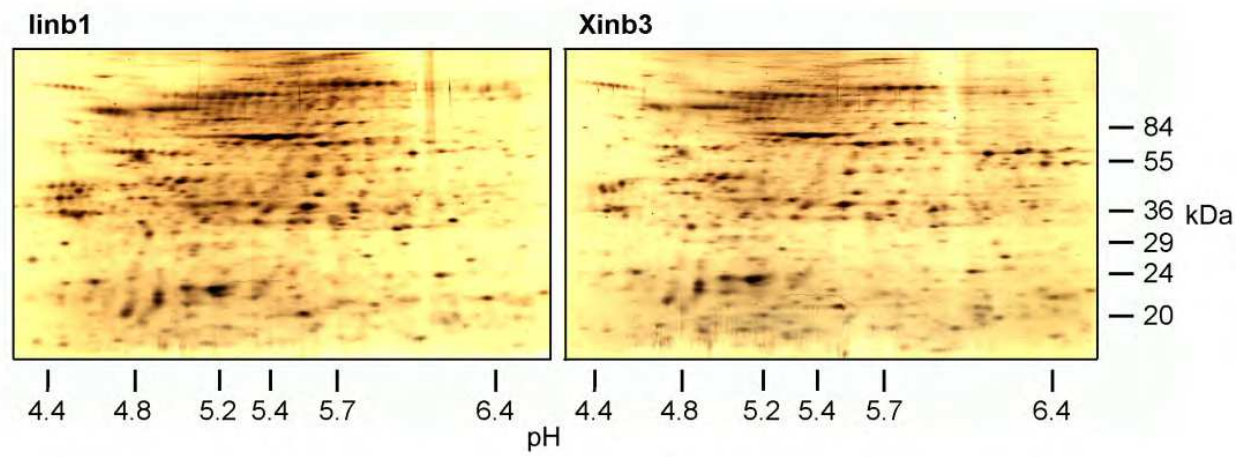

Fig. 1. Representative silver-stained 2D gels of individual Daphnia magna with distinct genotypes. Quadruplicate gels revealed $692 \pm 14$ spots in linb1 clone (left) and $687 \pm 11$ spots in Xinb3 clone (right).

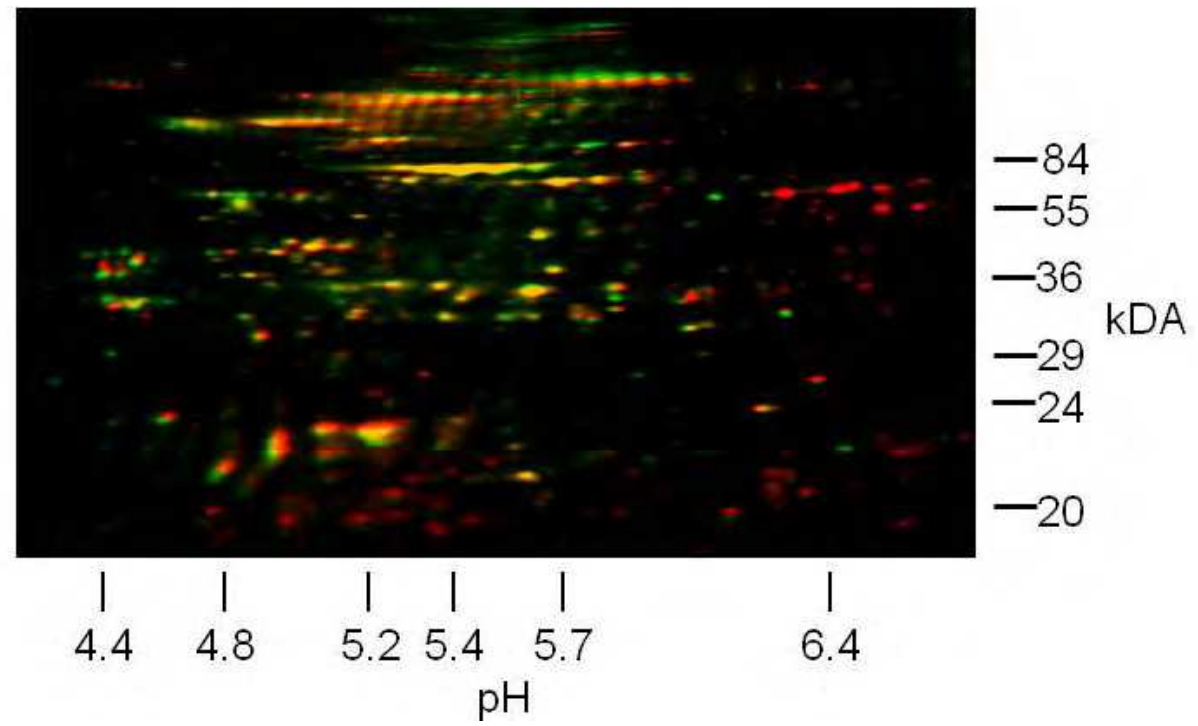

Fig. 2. Digitally enhanced, superimposed, silver-stained 2D gels of individual Daphnia magna with distinct genotypes. Red indicates spots unique to Iinb1, green indicates spots unique to Xinb3, yellow indicate spots shared by both genotypes. 


\subsection{Protein variation between individual $D$. magna of distinct phenotypes}

We were also able to detect differences between individual Daphnia with distinct phenotypic differences. Individual D. magna, with and without ephippia, were isolated, proteins extracted and analyzed by $2-\mathrm{DE}$ as described above. Silver staining detected an average of $524.5 \pm 7.8$ protein spots in $2 \mathrm{D}$ gels produced from single D. magna, with and without ephippia (figure 3). After normalization of the gel images based on total intensity, 386 spots were matched between the two gel images. Eighty-four spots showed a three-fold or greater difference in spot intensity. Fifty-five of these were more abundant in the parthenogenic (no ephippia) animal, while 29 were more abundant in the sexual animal. In addition, eleven protein spots were unique to the parthenogenic phenotype, while 49 protein spots were unique to the sexual phenotype. This demonstrates the feasibility of 2-DE and image analysis for the differentiation of Daphnia phenotypes isolated in the field as indicators of environmental variables. Other studies with parthenogenic and sexual Daphnia carinata were able to identify several proteins that were differentially expressed between the two phenotypes by 2-DE; however, 100's of animals were used (Zhang et al., 2006). It is interesting to note that using single animals, we discovered similar patterns of up-regulation in the parthenogenic individual in comparison to the sexual phenotype. While Zhang et al.'s goal was only to gain insight into the genes involved in the switch to sexual reproduction, our method, using single Daphnia magna with and without ephippia, allows the sampling of these candidate genes within a population.

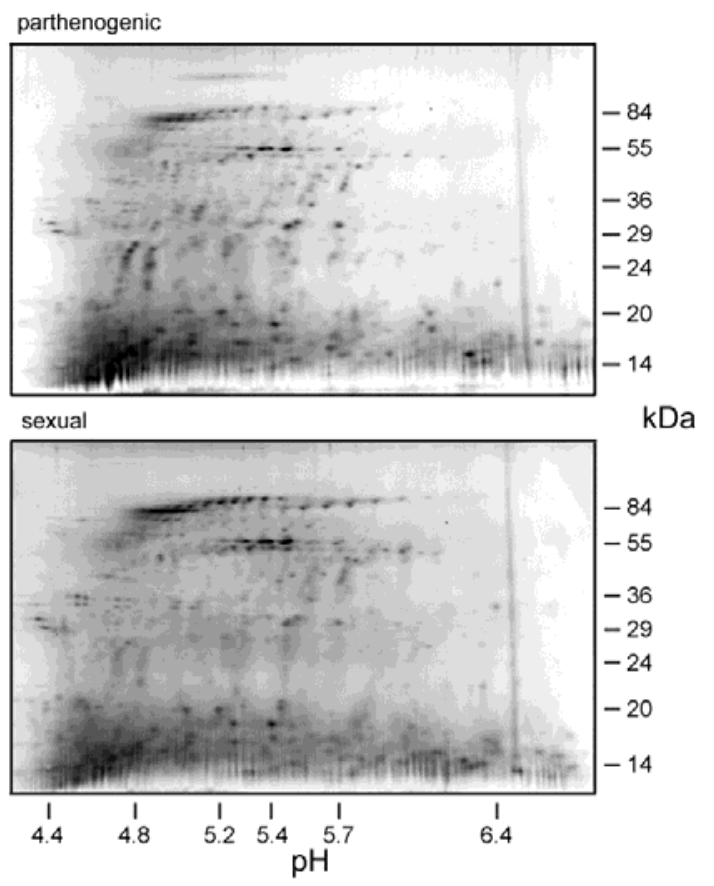

Fig. 3. Silver stained 2D gels of individual Daphnia magna with unique phenotypes. 


\subsection{Extending approach to single $D$. pulex}

As D. magna is the largest of the Daphnia genus, we used PCT to extract protein from single D. pulex to demonstrate that our technique would be feasible with smaller individuals. Even when using the much smaller Daphnia pulex, we were able to detect approximately 900 spots from a single individual. It is reasonable to expect that differences in 2-DE between single $D$. pulex with phenotypic differences would also be detectable. As an indication of reproducibility of our method, we ran duplicate 2-DE of PCT- extracted proteins from 1, 2, 3, 4 and 5 Daphnia pulex. Figure 4 shows representative gels of 1, 2 or 3 Daphnia pulex. Figure 5 shows the number of protein spots detected and the standard deviation for Daphnia pulex gels of 1, 2, 3, 4 and 5 individuals. The low standard deviation indicates that PCT and 2-DE is an efficient and highly reproducible method of sample preparation and protein comparison.
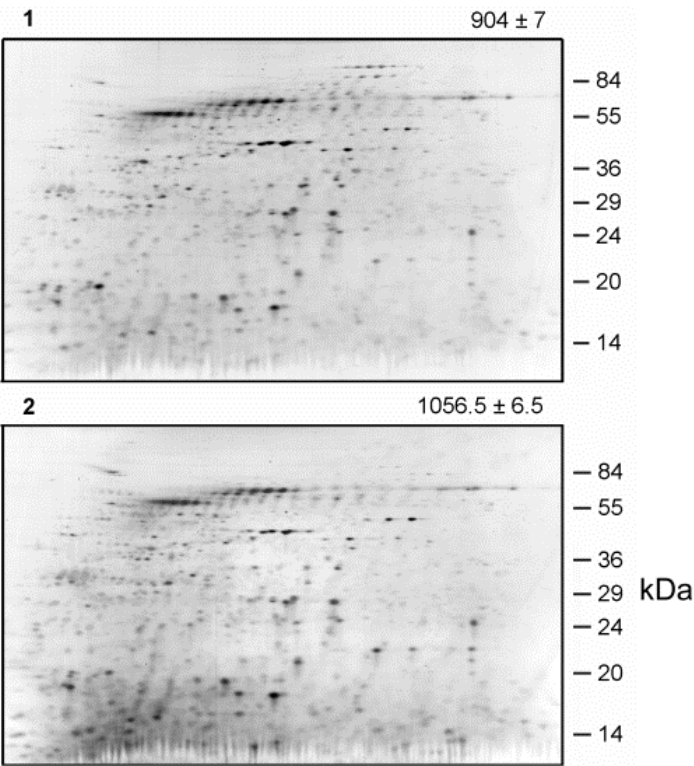

3

$1146 \pm 4$

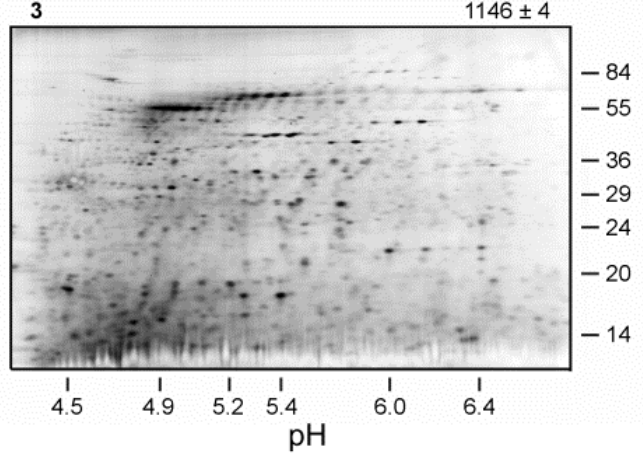

Fig. 4. Representative, silver stained 2D gels of 1, 2 \& 3 Daphnia pulex. 


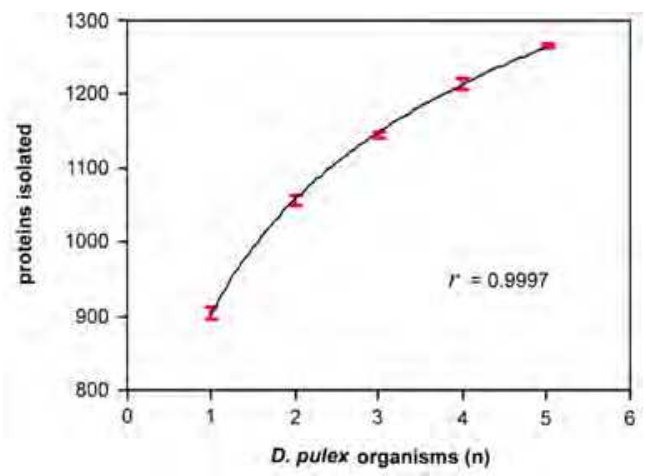

Fig. 5. Graph of detected protein spots from duplicate silver stained 2D gels of proteins extracted 1, 2, 3, 4 \& 5 Daphnia pulex. The shape of the curve suggests that our method is an efficient and reproducible approach to protein extraction and the majority of the unique proteins are recovered from a single animal.

\subsection{Protein functional diversity}

To properly evaluate our method, it is necessary to understand the functional diversity of the proteins sampled. The proteins detected on any 2D gel will be biased towards the most abundant and the goal is to sample gene expression for proteins of diverse functions. To evaluate the likely diversity of proteins detectable and comparable by this method, we first generated a theoretical 2D gel for the 2000 most highly expressed genes in the Daphnia pulex genome. The correlation between mRNA expression levels and protein abundance is a debated topic; (for a brief review, see Greenbaum et al., 2003) however, recent studies have found a high correlation (Lu et al., 2007; Tuller et al., 2007). Using the recently completed draft of the Daphnia pulex genome, we found the top 2000 gene prediction models with the most Expressed Sequence Tag (EST) evidence using BLAST (Altschul et al., 1990). The theoretical pI and MW of these genes were calculated using the Compute pI/MW tool from ExPASy (Gasteiger et al., 2003) and the results graphed using Excel to create the theoretical 2D gel (Figure 6). Importantly, the pI range used on the actual gels (indicated by the rectangle) covers a significant portion of the predicted proteome.

To assay the functional diversity of these theoretical proteins, we utilized the 25 eukaryotic orthologous groups (KOGs) (Totusov et al., 2003) that were assigned to the Daphnia pulex genes as part of the genome sequence annotation project. Many D. pulex genes have no homology to any entries at NCBI; therefore, it is not surprising that of the approximately 30,000 predicted genes only 18,371 have been assigned to a KOG class (Colbourne et al., 2011) Of the 2000 most highly expressed genes, 298 had been assigned to a KOG class. Twenty four of the 25 KOG classes were represented, and only "coenzyme transport and metabolism" was absent. To understand the functional diversity that may be present on a single animal 2D gel of approximately 1000 spots, we looked at the KOG assignments of the 1000 most highly expressed genes. Ninety-seven have been assigned to a KOG class, with 21 of the 25 KOG classes being represented. Not represented were 
"coenzyme transport and metabolism", "secondary metabolites, biosynthesis, transport and catabolism", "nuclear structure" and "chromatin structure and dynamics" (Figure 7). In general, KOG classes that are well represented in the Daphnia genome are also well represented in the top 2000 of most highly expressed genes. As $84 \%$ of the KOG classes are represented in the top 1000 most highly expressed genes, we feel that a single animal 2D gel of approximately 1000 spots should represent a diverse sampling of biologically relevant proteins.

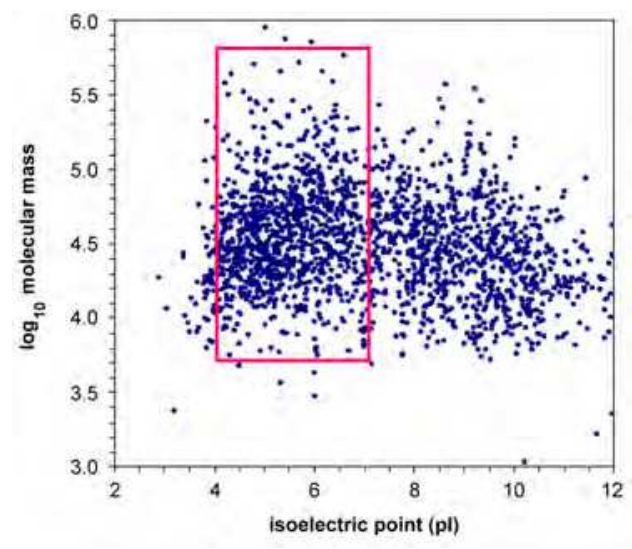

Fig. 6. Theoretical 2D gel of the top 2000 highly expressed D. pulex genes. The rectangle represents the separation range (MW and $\mathrm{pI}$ ) of actual 2D gels ( $\mathrm{pH}$ range $4-7$ ).

\begin{tabular}{ccccc} 
pI range & $\begin{array}{c}\text { number of } \\
\text { theoretical } \\
\text { proteins }\end{array}$ & $\begin{array}{c}\text { percent } \\
\text { of total } \\
\text { predicted }\end{array}$ & $\begin{array}{c}\text { number of } \\
\text { observed } \\
\text { proteins }\end{array}$ & $\begin{array}{c}\text { coefficient } \\
\text { of variation }\end{array}$ \\
\hline $3-4$ & 17 & 0.9 & - & - \\
$4-7$ & 1027 & 51.4 & $904.0 \pm 7.0^{b}$ & 0.008 \\
$7-10$ & 749 & 37.5 & $381.5 \pm 26.5^{c}$ & 0.069 \\
$>10$ & 207 & 10.4 & - & - \\
\hline total & 2000 & - & $1285.5 \pm 33.5$ & 0.026
\end{tabular}

a Proteins predicted from sequence does not account for charge

${ }^{b}$ Spots detected in 2D gels from single D. pulex organisms.

cSpots detected in 2D gels of a multiple D. magna organisms.

(184.0 $\pm 2.6 \mathrm{mg}$ or approximately 130 daphnids)

Table 1. Distribution of 2000 most abundant Daphnia proteins predicted from genome sequence 


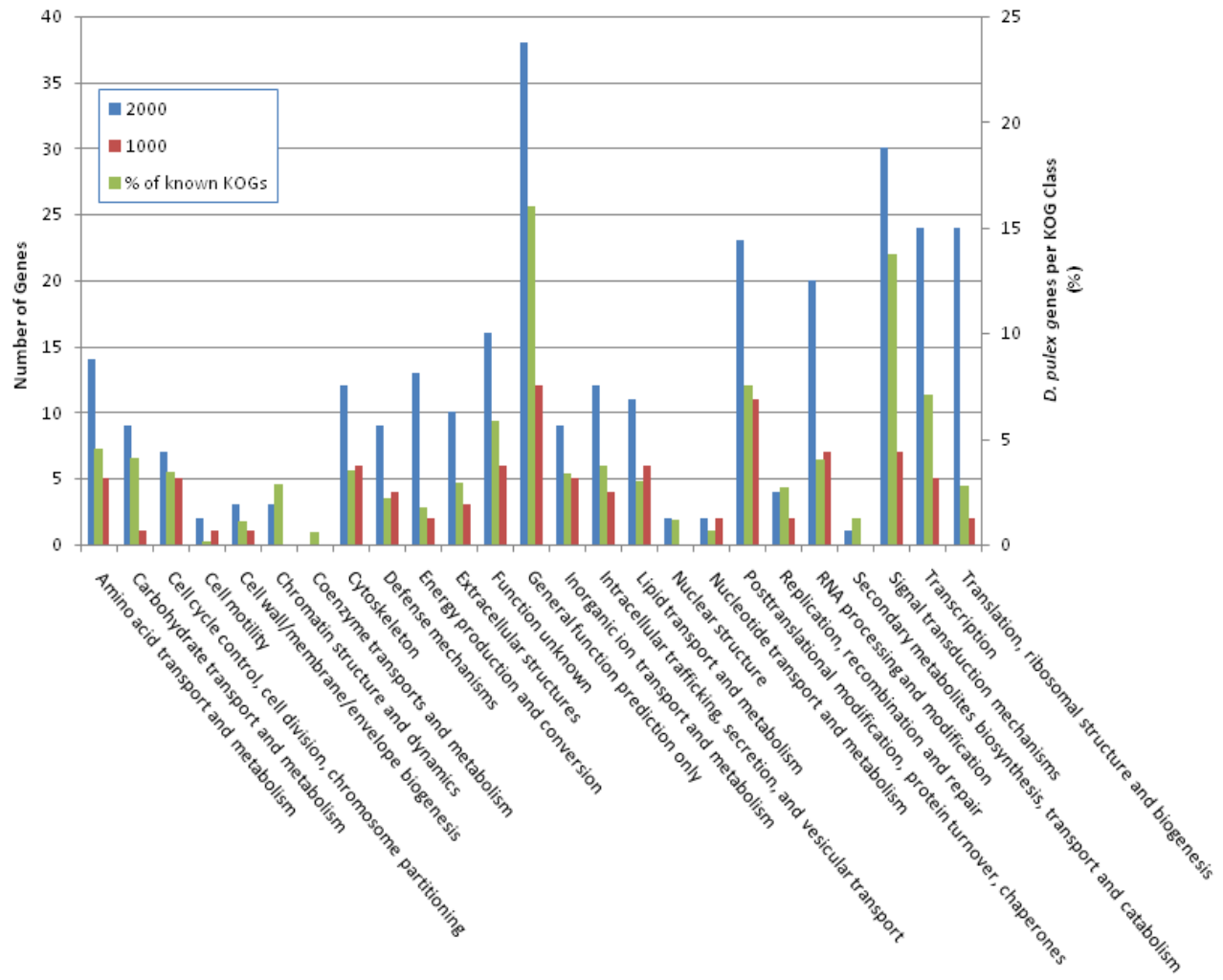

Fig. 7. Distribution of highly expressed D. pulex genes across 25 KOG classes. Blue and red bars indicate the number of genes in each class from the top 2000 and 1000, respectively, most highly expressed genes (Left-hand axis). Green bars indicate the total genes assigned to each KOG class as a percentage of the total number of genes $(18,371)$ assigned to a KOG class (Right-hand axis). To further characterize the predicted protein gel, we compared it to our observed spot counts. Table 1 summarizes the number of predicted proteins and the number of actual proteins within specific $\mathrm{pI}$ ranges. Through the generation of several D. magna (both single animal and multiple-animal) 2D gels (not shown), we were able to visualize a total of 1285 protein spots. Seventy percent of these were observed in the 4-7 $\mathrm{pI}$ range, while the theoretical gel predicted $51 \%$ in this same range. It is important to note that the theoretical $2 \mathrm{D}$ does not account for post-translational modifications and was generated from D. pulex genes. Both of these factors will contribute to differences between the predicted (D. pulex) and observed (D. magna) number of proteins. 


\subsection{Basic proteins constituents of the $D$. magna proteome}

Initially, single Daphnid extracts were analyzed on IPG strips with a $\mathrm{pH}$ range of 3-10. Since more than $80 \%$ of the proteins visualized by silver staining were in the $\mathrm{pH} 4-7$ range, subsequent analyses were performed using IPGs pH 4-7. However, the theoretical 2D does predict a significant number of proteins $(47 \%)$ in the basic range (7-10). Due to their relative low abundance, the visualization of very basic proteins $(\mathrm{pH} 7-10)$ in Daphnids required many more organisms. For this, $184 \pm 3 \mathrm{mg}$ of $D$. magna (approximately 135 organisms) were cultured under either normal or hypoxic conditions and processed in $1.3 \mathrm{~mL}$ of ProteoSOLVE IEF Reagent. The samples were concentrated two-fold by ultrafiltration, and IEF was performed on IPGs $\mathrm{pH}$ 7-10, followed by silver staining and image analysis. Silver staining detected 355 and 408 spots (gels not shown) in $\mathrm{pH}$ range 7-10 from D. magna cultured under normal or hypoxic conditions respectively, further illustrating the utility of 2-DE for detecting phenotypic differences influenced by specific environments.

\section{Conclusion}

Organisms live in ever changing environments. Understanding how individuals respond and adapt to these environments on a molecular level forms the basis for advances in personalized medicine and requires model systems with both well-developed ecological knowledge and molecular resources. The freshwater crustacean Daphnia now has these two requirements in place. We have demonstrated the ability of 2-DE to identify protein differences between single Daphnia magna with distinct genotypes (Iinb1 and Xinb3), distinct phenotypic differences (presence or absence of ephippia) and when cultured in different environments (normal or hypoxic conditions).

We predict that the detectable proteins on a single animal 2D gel, while biased towards the most abundant proteins, represent a functionally diverse set of proteins. This technique represents an important step to a greater understanding of individual variation of gene expression and is critical to advancing the field of EEFG. However, as the use of silver stain convolutes downstream mass spectrometry, the number of protein spots that can be confidently identified is significantly curtailed. The full potential of single animal gels will be realized with the development of comprehensive 2D maps of the Daphnia proteome.

\section{References}

Altschul SF, Gish W, Miller W, Myers EW, \& Lipman DJ. 1990. Basic local alignment search tool. Journal of Molecular Biology, 215(3):403-410.

Colbourne J.K., et. al., 2011. The Ecoresponsive Genome of Daphnia pulex. Science, Feb 4; 331(6017): 555-61.

Edmondson WT. 1987. Daphnia in Experimental Ecology: Notes on Historical Perspectives. In: Peters RH, R. dB, editors. Daphnia. Pallanza: Memorie dell'Instituto Italiano di Idrobiologia, 45:11-30.

Gasteiger E, Gattiker A, Hoogland C, Ivanyi I, Appel RD \& Bairoch A. 2003. ExPASy: The proteomics server for in-depth protein knowledge and analysis. Nucleic Acids Research, 31(13):3784-3788.

Geiser HA, Hanneman AJ, \& Reinhold V. 2002. HTP proteome-glycome analysis in Caenorhabditis elegans. Glycobiology, 12(10):650. 
Greenbaum D, Colangelo C, Williams K, \& Gerstein M. 2003. Comparing protein abundance and mRNA expression levels on a genomic scale. Genome Biology, 4(9):117.

Hairston NG, Jr., Holtmeier CL, Lampert W, Weider LJ, Post DM, Fischer JM, Caceres CE, Fox JA, \& Gaedke U. 2001. Natural selection for grazer resistance to toxic cyanobacteria: Evolution of phenotypic plasticity?, Evolution, 55(11): 2203-2214.

Kilham SS, Kreeger DA, Lynn SG, Goulden CE, \& Herrera L. 1998. COMBO: a defined freshwater culture medium for algae and zooplankton. Hydrobiologia, 377:147-159.

Limburg PA, \& Weider LJ. 2002. 'Ancient' DNA in the resting egg bank of a microcrustacean can serve as a palaeolimnological database. Proceedings of the Royal Society of London:Series B, 269:281-287

Lu P, Vogel C, Wang R, Yao X, \& Marcotte EM. 2007. Absolute protein expression profiling estimates the relative contributions of transcriptional and translational regulation. Nature Biotechnology, 25(1):117-124.

National Science Board. 2000. Environmental Science and Engineering for the 21st Century: The role of the National Science Foundation. Report number: NSB 00-22.

Rottu J, Jansen B, Colson I, De Meester L, \& Ebert D. 2010. The first-generation Daphnia magna linkage map. BMC Genomics, 11:508.

Smejkal GB, Li C, Robinson MH, Lazarev AV, Lawrence NP, \& Chernokalskaya E. 2006a. Simultaneous reduction and alkylation of protein disulfides in a centrifugal ultrafiltration device prior to two-dimensional gel electrophoresis. Journal of Proteome Research, 5(4):983-987.

Smejkal GB, Robinson MH, Lawrence NP, Tao F, Saravis CA, \& Schumacher RT. 2006b. Increased protein yields from Escherichia coli using pressure-cycling technology. Journal of Biomolecular Techniques, 17(2):173-175.

Smejkal GB, Witzmann FA, Ringham H, Small D, Chase SF, Behnke J, \& Ting E. 2007. Sample preparation for two-dimensional gel electrophoresis using pressure cycling technology. Analytical Biochemistry, 363(2):309-311.

Tatusov RL, Fedorova ND, Jackson JD, Jacobs AR, Kiryutin B, Koonin EV, Krylov DM, Mazumder R, Mekhedov SL, Nikolskaya AN, Rao BS, Smirnov S, Sverdlov AV, Vasudevan S, Wolf YI, Yin JJ, \& Natale DA. 2003. The COG database: an updated version includes eukaryotes. BMC Bioinformatics, 4:41.

Tuller T, Kupiec M, Ruppin E. 2007. Determinants of Protein Abundance and Translation Efficiency in S. cerevisiae. PLoS Computational Biology, 3(12):e248.

Zhang M-F, Zhao Y-L, \& Zeng C. 2006. Differential protein expression between parthenogenetic and sexual female of Daphnia (Ctenodaphnia) carinata. Acta Zoologica Sinica, 52(5):916 -923. 


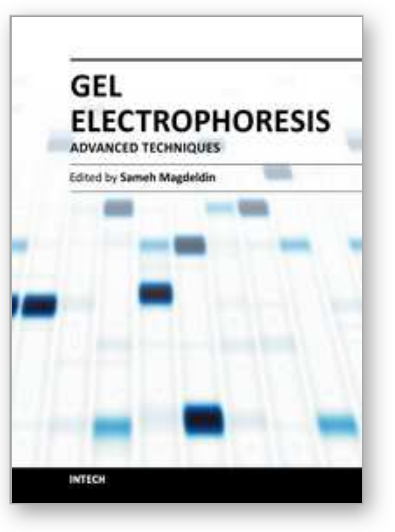

\author{
Gel Electrophoresis - Advanced Techniques \\ Edited by Dr. Sameh Magdeldin
}

ISBN 978-953-51-0457-5

Hard cover, 500 pages

Publisher InTech

Published online 04, April, 2012

Published in print edition April, 2012

As a basic concept, gel electrophoresis is a biotechnology technique in which macromolecules such as DNA, RNA or protein are fractionated according to their physical properties such as molecular weight or charge. These molecules are forced through a porous gel matrix under electric field enabling uncounted applications and uses. Delivered between your hands, a second book of this Gel electrophoresis series (Gel Electrophoresis- Advanced Techniques) covers a part, but not all, applications of this versatile technique in both medical and life science fields. We try to keep the contents of the book crisp and comprehensive, and hope that it will receive overwhelming interest and deliver benefits and valuable information to the readers.

\title{
How to reference
}

In order to correctly reference this scholarly work, feel free to copy and paste the following:

Darren J. Bauer, Gary B. Smejkal and W. Kelley Thomas (2012). Two-Dimensional Gel Electrophoresis Reveals Differential Protein Expression Between Individual Daphnia, Gel Electrophoresis - Advanced Techniques, Dr. Sameh Magdeldin (Ed.), ISBN: 978-953-51-0457-5, InTech, Available from: http://www.intechopen.com/books/gel-electrophoresis-advanced-techniques/two-dimensional-gelelectrophoresis-reveals-differential-protein-expression-between-individual-daphn

\section{INTECH}

open science | open minds

\section{InTech Europe}

University Campus STeP Ri

Slavka Krautzeka 83/A

51000 Rijeka, Croatia

Phone: +385 (51) 770447

Fax: +385 (51) 686166

www.intechopen.com

\author{
InTech China \\ Unit 405, Office Block, Hotel Equatorial Shanghai \\ No.65, Yan An Road (West), Shanghai, 200040, China \\ 中国上海市延安西路65号上海国际贵都大饭店办公楼 405 单元 \\ Phone: +86-21-62489820 \\ Fax: $+86-21-62489821$
}


(C) 2012 The Author(s). Licensee IntechOpen. This is an open access article distributed under the terms of the Creative Commons Attribution 3.0 License, which permits unrestricted use, distribution, and reproduction in any medium, provided the original work is properly cited. 